\title{
Hijab(istas)—as Fashion Phenomenon. A Review
}

\author{
Laura NISTOR \\ Sapientia Hungarian University of Transylvania \\ Cluj-Napoca, Romania \\ nistor.laura@uni.sapientia.ro
}

\begin{abstract}
In the present article, I am shortly reviewing some aspects which can be regarded as important in considering the hijab a fashion phenomenon. The social media provides us with various images in which the hijab is presented as a form of fashionable accessory, it is adapted to various modern outfits. The literature on such fashionable takes of the hijab assesses that they can be interpreted as statement messages about women's empowerment. On the other hand, such adaptations also speak about the emergence of various subcultures about Muslim youth, which in accordance with the global sameness of youth are using social media in order to send messages and connect with each other. After a brief presentation on the role of bottom-up diffusion of fashion innovations, I am reviewing, grosso modo, two representations of the hijab: the hijab as a religious symbol and the hijab as a (fashion) manifesto about women's empowerment.
\end{abstract}

Keywords: hijab, fashion, subculture, manifesto

\section{Introduction}

The different cultural and religious background seems to underline the different size model, style, and also color and material of the hijab, i.e. khimar (according to the Qur'anic religious command women being required to cover their head). According to ethnicity and culture, region or tribe, Muslim women's veil appears in a large variety of styles and denominations, encapsulated in certain cultural frames: 'abaya in Arabia, chador in Iran; burqa in Afghanistan; niqab in Muslim India or purdah in Muslim Pakistan; kerudung in Malaysia and Indonesia; buibui in East Africa; a bigger scarf over the head in Western countries, largely named "hijab". ${ }^{1}$ The interplay between culture and religion

1 https://www.al-islam.org/hijab-muslim-womens-dress-islamic-or-cultural-sayyid-muhammadrizvi/muslim-culture-style-hijab. 
also gives place to the making of the fashion history and style dynamics of the hijab.

The literature as well as a simple scrolling on social media platforms (i.e. Instagram, Facebook, and blogs) show many hashtags ${ }^{2}$ incorporating the hijab in fashion-related images and narratives. Through such attitudes and practices, young Muslim women living mostly in Western cultural contexts (but even their peers living in traditional Muslim societies) show their cool, fashionable take on hijab by integrating it with modern, fashionable clothes and brands. Obviously, such consumerist and creative adaptations of the hijab have a diverse motivational base and can be read both in terms of the "laicization" of the veil ${ }^{3}$ and as a manifesto of young Muslim women in terms of their independence. In this latter sense, the literature speaks even about the emergence of various hijab-fashion subcultures among young Muslim women (cf. generation M). ${ }^{4}$

The growing street-style and digital presence of generation $M$ determines a phenomenon of imitation (i.e. fashion diffusion), and so we are facing a situation when subcultural and street-style takes on hijab become inspirations for the creations of high-fashion houses (e.g. Dolce \& Gabbana ${ }^{5}$ in 2016) as well. Whichever would be the reason of presenting high-fashion collections which incorporate the veil (e.g. appealing to Muslim population, manifesting against stereotypes and stigmatization), such situations are examples for the so-called bottom-up diffusion of fashion, when the ideas of high-fashion creators are rooted in the practices coming from popular culture.

Following a brief presentation on the role of bottom-up diffusion of fashion innovations, I am going to juxtapose, grosso modo, two representations of hijabthe former insisting on the hijab as a religious symbol and the second taking it as a manifesto and integrating it into fashionable (life)styles. The last part will discuss further this phenomenon of adaptation and the possible emergence of hijab-related subcultures.

2 For instance, Instagram revealed 1,688,179 public posts having attached \#hijabista (last count on June 4, 2017).

3 And in this sense, such practices can be considered arguments against Barnard's (1996/2002) opinion that traditional, religious dresses and uniforms can be considered solely as clothes and they cannot be referred as fashion.

4 The definition given by Janmohamed (2016) to young Muslim women living in global cities who try to connect traditional Muslim and modern values and spread their ideas through social media.

5 The Vogue presented the collection like this: "The garments, while engineered for modesty, have all the flair of any other Dolce \& Gabbana collection-a little jewel-encrusted lemon here, some black lace trim there-and are styled alongside the label's cocktail jewelry, oversize sunglasses, and patterned bags in a lookbook shoot. To Muslim women with a taste for luxury fashion, this collection is an exciting development" (Yotka, 2016 in Vogue, January 5, 2016 http://www.vogue.com/article/dolce-gabbana-hijab-abaya-collection). 


\section{Fashion and fashion diffusion}

Fashion can be defined in multiple ways depending on which aspects of the phenomenon are accentuated. ${ }^{6}$ Out of the many approaches of fashion, Miller's (2005) viewpoint is particularly useful and appealing to me as far as it captures both the macro- and micro-level of the phenomenon. Thus, fashion can refer both to specific (trendy) clothes of a specific era, season, place, or group and to the public presentation of the self with the help of clothes, i.e. to identity construction. It follows that individuals rarely dress in an isolated manner, and dress is a less personal thing than it might seem: in their clothing choices, individuals rely on personal role models, bear in mind their affiliation and distinction needs to and from certain groups, can provide more or less radical messages about their preferences, etc. ${ }^{7}$

Fashion is a dynamic phenomenon because it suffers frequent changes depending on cultural, social, economic, political, and aesthetic contexts; fashion trends emerge, get adopted or not, and finally are disappearing (Kim et al. 2014). Fashion changes in relationship to social institutions, power relations, etc. Thus, in the postmodern society, fashion is more democratic as it was in the course of early modern times; there are different styles with specific publics which co-exist and the agreements about fashion standards are more flexible than ever (Crane 2012). Consequently, in the late modern societies, fashion dissemination occurs not only/ not necessarily from high-fashion houses (i.e. elites) towards non-elites but also from the street towards elites, in the sense that role models from popular culture corresponding to specific cultural niches, and thus having their specific public, can launch and spread specific fashion styles (Crane 2012).

As a consequence, postmodern approaches of fashion speak about a reverse diffusion, i.e. about a bottom-up diffusion of fashion, which means that no matter what is the socio-economic background of the individuals, they can give rise to new styles, which then can be adopted by peer-groups, then by larger and larger masses and, eventually, by high-fashion houses as well. Subcultures are highly illustrative in this sense: youth, artists as well as different minority groups can create their specific clothing styles either in order to protest or simply in order to individualize and distinct themselves from the masses (cf. Crane 1999). Such dynamic, bottom-up processes of fashion diffusion became widespread not only due to the wide process of globalization but also due to the instrumental help of the so-called "electronic fashion worlds" (cf. Crane 1999), i.e. social media,

6 For instance, Crane (2012) contends that fashion can be seen as a form of material culture which includes clothing and bodily decoration; as signifier, i.e. a language in which different styles have the function of signs; as art and business of fashion creation, communication, and distribution; as instrument of social differentiation and mobility.

7 In this respect, fashion subcultures are illustrative: through the power of dress and rituals, subordinated groups are expressing their ideas about society, challenge the values of the majority, of specific eras, etc. and are providing new approaches concerning social order (Hebdige 1979). 
which serves as a repository and sharing platform for both street style fashion icons and personal takes on fashion.

\section{Being cool in hijab}

In the contexts of these postmodern bottom-up diffusions of fashion, it is always interesting to see what happens to the traditional clothing styles of specific groups, i.e. ethnic or religious communities. In this respect, to what extent globalization per se, consumer culture, liquid modernity, youth subcultures, but also nowadays' turbulent times in terms of terrorist attacks, the problematic nature of assimilation and discrimination, contradictory attitudes towards migration, etc. influence the wearing of the hijab in non-Muslim contexts represent exciting questions.

Hijab is a Muslim veil whose roots can be traced back to ancient Mesopotamia, where veiling was the symbol of nobility. Later on, the veil got religious meanings, being assimilated to the teaching of the Qur'an and considered the symbol of modesty (Bartowski and Read 2003). Non-Muslim common sense often interprets the hijab as a symbol of Muslim identity and reads it in terms of gender inequality and women's oppression (Williams and Vaschi 2007). The literature on hijab presents two opposing views: oppression and liberation. The first perspective goes hand in hand with the common sense and sees the hijab as the visual representation of patriarchal dominance and oppression (Papanek 1973); accordingly, wearing the hijab results in the victimization of Muslim women especially by outsiders, i.e. by exponents of other cultures (Alvi et al. 2003).

The other perspective sees the wearing of the hijab as a manifestation of independence and empowerment (Alvi et al. 2003). Muslim women, particularly those who live in secular Western societies, do not necessarily associate it with Islam religiosity; for them, the choice of wearing the hijab and adapting it to various non-religious contexts and clothing styles can have various motivations ${ }^{8}$ and represents a complex act of identity construction (Williams and Vashi 2007).

8 The literature contends that through wearing the hijab Muslim women are creating a kind of individual, intimate, and cultural space around them (Bartowski and Read 2003, Williams and Vaschi 2007). Being placed in Western contexts, the hijab can be read also as a subcultural attitude because it often challenges the reactions of the dominant culture and thus serves also as a manifesto against prejudice. Such rebellious attitudes can be also found in those kinds of motivation which assess that the hijab can be worn by young women in spite of the fact that their family does not impose it. Thus, by taking a more conservative attitude in terms of outfits, young women may try to escape other types of pressures on the part of their families, e.g. marriage. The motivation for wearing the hijab can also be a critical attitude towards globalization and towards the objectification of women in global culture (Williams and Vaschi 2007). Other reasons for wearing the veil include civic duties like raising awareness about Islam and fighting stereotypes concerning the Muslim community (Zine 2001). The hijab can also serve aspirations in terms of career and upward social mobility (Bartowski and Read 2003). 
Thus, the hijab as a clothing item specific to Muslim women can be considered a fashion instrument through which they express both their need of affiliation and differentiation to and from certain groups (e.g. the Muslim community and the outsider society). ${ }^{9}$ Obviously, as far as the hijab is considered by Western society as a religious symbol and, consequently, as something dangerous on secularism (Wallach Scott 2007), the dominant society can exhibit various forms of hostile reactions towards the veil, which can reach their peak in the official banning of the veil in public spaces (e.g. the case of France) ${ }^{10}$ based on the argument that such measures promote integration (Walach Scott 2007). ${ }^{11}$

As far as the wearing of the hijab and the ways in which it is worn can have various motivations and associated benefits and risks, contemporary literature sees the hijab not only as a community-level action attached to religious affiliation but considers it also in terms of individual agency. Thus, Tarlo (2007) contends that in the context of multicultural, global cities, the hijab becomes the symbol of visibility and manifestations of particular values which go well beyond asserting one's religion and ethnicity. By incorporating it in diverse outfits, the hijab can serve various individual purposes, and individuals decide whether to adopt, adapt, or abandon (Williams and Vaschi 2007) the hijab depending on their status and aspirations. Almila (20016) contends in the same line that in Western contexts the hijab has different ways of wearing, which all can manifest a woman's specific attitude towards fashion and society in general. By researching Muslim women in Finland, the author found three kinds of attitudes in this sense labeled as fashion, anti-fashion, and nonfashion. All these attitudes depend on women's social position: lower class women with conservative values employ the hijab as a strategy of anti-fashion

$9 \quad$ In any case, both the acts of wearing and abandoning the hijab are acts of courage because as members of minority groups women have to take into account both the reactions of the minority and of the dominant society (Almila 2016). From this perspective, modernist approaches of the hijab by young Muslim women, i.e. the integration of the veil in consumerist lifestyles, can provoke different reactions from the part of their Muslim community and from the part of their non-Muslim peers and non-Muslim society in general. That is, hostile reactions towards wearing, abandoning, or adapting the veil does not come solely from non-Muslim people. In the context of global consumer culture (and in the context of living in more or less secular non-Muslim countries), wearing the hijab can be interpreted both in terms of demonstrations of difference and in terms of taking the risk of being discriminated by the majority. The literature contends, indeed, that such kind of discrimination can result in two types of strategies in nonMuslim contexts: one of these is to take off the hijab-and that was observed in the context of post-9/11 events when the Muslim population was stigmatized as a whole: women abandoned the hijab because of fear (Badr 2004). On the other hand, many Muslim women who had not worn hijab before the attacks started to wear it after the attacks in order to manifest against the stigmatization.

10 Seen from this angle, the case is similar to societies' reactions towards subcultures as far as the hijab becomes a catalyst for moral panic and labeling (cf. Hebdige 1979).

11 The author contends that in spite of the slogan of promoting integration such prohibitions are expressing French and other dominant cultures' failure in integration and in dealing with difference. 
or non-fashion and wear it in a traditional form, in combination with other nonfashionable clothes, while those with carrier aspirations use it as a fashionable object and combine it with trendy garments in such a way that the appearance of these women replicates the fashion style of western middle-class women (cf. Williams and Vaschi 2007).

Wearing the hijab in innovative forms, mostly by combining it with high or fast fashion items, is an example for cultural hybridization (Ritzer 1993/2004) and also speaks about the visual translation of class through the veil: by wearing it in certain ways, women speak both about their ethnicity and status aspirations in education, career, etc. (Appleford 2013—qtd by Almila 2016).

In this context, the case of the hijabistas ${ }^{12}$ becomes particularly interesting. Such women can be described as young middle-class members who wear the veil in fashionable forms and make this stance visible on social media (Beta 2014). Thus, via the Internet, these women can form virtual communities linked together through hashtags. In their posts, the hijab becomes a symbol of the modern Muslim woman who cares about fashion and-despite illustrating the omnipresence of consumer culture-who is also illustrative for the ways in which the hijab can become a form of empowerment, a fashion statement which speaks about women's aspiration. Hijabistas give a different meaning to the hijab: it is not the symbol of modesty (as it was once perceived) anymore but that of the ways in which women can speak about themselves with the help of fashion (Beta 2014), an instrument of reconciling different values of Muslim and modern culture.

Analyzing the case of these young Muslim women, the literature speaks about a "new veiling movement" or about a young subculture among Muslim women, called Mipsters (Kuriata 2016), which is illustrative not only for the fashionable takes on veiling (i.e. laicization of the hijab) but also for the incorporation of the veil in garments which are specific for different subcultures (e.g. punk). Through such adaptations, Mipsters are practising not only a so-called "covered chic" (Kuriata 2016) but are also using the language of fashion to show specific identities and to resist stereotypes (Alvi 2013); they want "both to affiliate to their Muslim communities and to outreach across wider society" (Janmohamed 2016: 13-14) with various messages. The cases of Niqua Bitch ${ }^{13}$ and Princess $\mathrm{Hijab}^{14}$ are edgy but also illustrative in this respect (cf. Moors 2011), and both

12 The term is a combination between hijab and fashionista, making also reference to Instagram. The literature uses various denominations for young Muslim women who share their fashionable wearing of the hijab on social media platforms: e.g. hijabers, hijabistas, Mipsters, etc.

13 NiqaBitch was a demonstration in 2010 against France's ban on wearing the hijab in public spaces and included two young women, wearing hot pants and niquab and thus creating a provocative outfit. They walked dressed like this on the streets of Paris and uploaded the video of their walk on the YouTube channel. The history of this civic action can be documented also from the blog of the NiqaBitches (http://niqabitch-blog.tumblr.com/).

14 Princess Hijab is an anonymous street artist working in Paris who paints hijabs on the faces of advertising figures from the Paris metro. Her actions are called hijabisations. 
are representing provocative adaptations of the hijab in order to raise awareness about dominant societies’ intolerant attitudes towards Muslims.

\section{Final remarks}

As far as fashion and identity are impossible to separate, fashion through its symbolism and its direct and indirect effects becomes an important indicator of personal and cultural identification. The transnational cultural and religious disseminations of different styles gave fashion an added value in terms of cultural and religious messages. In this respect the hijab-related fashion shows the different ethnographic components of various cultures and also a reflection on current socio-economic phenomena. The growing interest towards Muslims and in general towards Eastern cultures is visible in the designs of high-fashion houses, but, vice versa, we are also witnessing the incorporation of Western garments and styles in the clothing of Muslims. Nowadays, to wear a hijab does not indicate solely the religious affiliation but also social status, affiliation to various subgroups, and a kind of distinctive manifesto.

It can be concluded that by taking more or less radical adaptation on the hijab and sharing their fashion posts on social media, generation $\mathrm{M}$ women speak not only about the omnipresence of the consumption culture but are also providing messages-with help of the language of fashion-on Muslim female's fashion and civic consciousness. While being fashionable in hijab illustrates the democratic nature of fashion in the era of postmodernity, being edgy and provocative in hijab (e.g. Mipsters) can be considered a form of resistance (Ameli and Merali 2006) which challenges the tolerance of both Muslim and non-Muslim cultures. Whether we are speaking about softer or harder adaptations, both cases are illustrative for the power of fashion language in the case of a clothing item which is often regarded as traditional, oppressive, and incapable of change.

\section{References}

Almila, Anna-Mari. 2016. Fashion, Anti-Fashion, Non-Fashion and Symbolic Capital. The Uses of Dress among Muslim Minorities in Finland. Fashion Theory 20: 81-102.

Alvi, Anjum. 2013. Concealment and Revealment. The Muslim Veil in Context. Current Anthropology 54: 177-199.

Alvi, Sajida, Hoodfar, Homa, McDonough, Sheila (eds.). 2003. The Muslim Veil in North America. Toronto: Women's Press. 
Ameli, Saied R., Merali, Arzu. 2006. Hijab, Meaning, Identity, Otherization and Politics: British Muslim Women. Islamic Human Rights Commission. (https:// books.google.ro/books/about/Hijab_Meaning_Identity_Otherization_and. html?id=gdVjq0nMtxgC\&redir_esc=y - last visit on: May 5, 2017).

Badr, Hoda. 2004. Islamic Identity Re-Covered: Muslim Women after September $11^{\text {th }}$. Culture and Religion 5: 321-338.

Barnard, Malcom. 1996/2002. Fashion as Communication. London: Routledge. Bartkowski, John P., Read, Jen'nan Ghazal. 2003. Veiled Submission: Gender, Power, and Identity among Evangelical and Muslim Women in the United States. Qualitative Sociology 26: 71-92.

Beta, Annisa R. 2014. Hijabers. How Young Urban Muslim Women Redefine Themselves in Indonesia. The International Communication Gazette 76: 377-389. Crane, Diane. 1999. Diffusion Models and Fashion. A Reassessment. The Annals of the American Academy of Political and Social Science 566: 13-24.

2000. Fashion and Its Social Agendas. Class, Gender, and Identity in Clothing. Chicago: University of Chicago Press.

Hebdige, Dick. 1979. Subculture. The Meaning of Style. London: Routledge.

Janmohamed, Shelina Zahra. 2016. Generation M. Young Muslims Changing the World. London: I. B. Tauris.

Kim, HaeJung, Ahn, Soo-Kyoung, Forney, Judith A. 2014. Shifting Paradigms for Fashion: from Total to Global to Smart Consumer Experience. Fashion and Textiles 1: 1-15.

Kuriata, Agnieszka. 2016. Hijab - Muslim Response to Globalization? Człowiek i Społeczeństwo XLV: 147-161.

Miller, Joshua I. 2005. Fashion and Democratic Relationship. Polity 37: 3-23.

Moors, Annelies. 2011. NiqaBitch and Princess Hijab. Niquab Activism, Satire, and Street art. Feminist Review 98: 128-135.

Papanek, Hanna. 1973. Purdah: Separate Worlds and Symbolic Shelter. Comparative Studies in Society and History 15: 289-325.

Ritzer, George. 1993. The McDonaldization of Society. Thousand Oaks: Pine Forge Press.

Rizvi, Sayyid Muhammad. 1997. Hijab, the Muslim Women's Dress, Islamic or Cultural? Ja'fari Islamic Centre (Tabligh Committee) Canada. (https://www.alislam.org/hijab-muslim-womens-dress-islamic-or-cultural-sayyid-muhammadrizvi/muslim-culture-style-hijab - last visit on: May 5, 2017).

Tarlo, Emma. 2007. Hijab in London. Metamorphosis, Resonance and Effects. Journal of Material Culture 12: 131-156.

Wallach Scott, Joan. 2007. The Politics of the Veil. Princeton: Princeton University Press.

Williams, Rhys H., Vaschi, Gira. 2007. Hijab and American Muslim Women. Creating the Space for Autonomous Selves. Sociology of Religion 68: 269-287. 
Yotka, Steff. 2016. Dolce \& Gabbana's Embellished Hijabs and Abayas Are Great News for Muslim Women-When Will Other Brands Follow Suit? Vogue, January 5, 2016. (http://www.vogue.com/article/dolce-gabbana-hijab-abaya-collection last visit on: May 5, 2017).

Zine, Jasmin. 2001. Muslim Youth in Canadian Schools: Education and the Politics of Religious Identity. Anthropology \& Education Quarterly 32: 399-423. 